\title{
Phototransistor Device
}

National Cancer Institute

\section{Source}

National Cancer Institute. Phototransistor Device. NCI Thesaurus. Code C50099.

A transistor in which incident light acts as the base activating input. 